\title{
Cross-Linking of Sulfonated Polylether ether ketone) by Thermal Treatment: How Does the Reaction Occur?
}

\author{
B. Maranesi ${ }^{1}$, H. Hou ${ }^{2}$, R. Polini ${ }^{1}$, E. Sgreccia ${ }^{1}$, G. Alberti ${ }^{3}$, R. Narducci ${ }^{3}$, P. Knauth ${ }^{2}$, \\ M. L. Di Vona ${ }^{1 *}$ \\ 1 Univ Roma Tor Vergata, Dip. Scienze e Tecnologie Chimiche, 00133 Roma, Italy \\ 2 Aix-Marseille Univ-CNRS, Laboratoire Chimie Provence (UMR 6264), Centre St Jérôme, 13397 Marseille, France \\ 3 Univ Perugia, Dip. Chimica, 06123 Perugia, Italy
}

Received January 20, 2012; accepted September 24, 2012; published online February 18, 2013

\section{Abstract}

The cross-link reaction between macromolecular chains of sulfonated poly(ether ether ketone) (SPEEK) by thermal treatment above $150^{\circ} \mathrm{C}$ in presence of dimethylsulfoxide (DMSO) is investigated by various techniques, including elemental analysis, acid-base titration, infrared spectroscopy, water uptake (WU) measurements, and thermogravimetry. The conditions of thermal treatment are analyzed. The crosslinking reaction occurs in at least three more or less activated and deactivated positions with different activation energies,

leading to different time dependencies of the cross-link reaction. The role of residual solvent DMSO is studied particularly: the cross-linking depends significantly on the amount of solvent in the membranes. Implications on WU and thermal stability are of particular importance for the development of high performance proton-conducting membranes.

Keywords: Fuel Cell, Hydrocarbon Polymer, Polymer Electrolyte, SPEEK

\section{Introduction}

The proton conducting membrane is a vital component of a polymer electrolyte membrane fuel cell (PEMFC); it allows proton migration and separates electrically and mechanically the cathode and the anode [1]. Sulfonated aromatic polymers (SAPs) might replace Nafion as proton-conducting membranes in PEMFCs and water electrolyzers, if problems related to degradation at temperatures above $80{ }^{\circ} \mathrm{C}$ can be solved [2-6]. In principle, SAP combine appealing properties, including high thermal and chemical stability, easy availability and low cost $[7,8]$, but the decrease of mechanical, hydrolytic and proton conduction properties observed above $80{ }^{\circ} \mathrm{C}$ limits currently their practical use in fuel cells as well as in other electrochemical devices [9-11]. The origin of this degradation is not yet completely understood and different hypotheses can be found in the literature, such as water loss or irreversible morphological changes of macromolecular chains [12-15]. It was also reported that casting solvents and the presence of residual sulfuric acid inside polymers can affect performances of these membranes [16]. For these reasons, SAP and in particular sulfonated poly(ether ether ketone) (SPEEK) are currently considered unsuitable for fuel cell application by a large part of the scientific community.

The development of novel proton-conducting membranes based on cross-linked SAP exhibiting properties comparable to or even better than those of perfluorinated sulfonic acid (PFSA) membranes and having an appreciably lower cost is one important aim of the LoLiPEM (Long-life PEMFCH\&CHP systems at temperatures $\geq 100{ }^{\circ} \mathrm{C}$ ) project supported by the European Commission (FP7) and by the Fuel Cells and Hydrogen Joint Undertaking (FCH JU) [17].

Cross-linking ( $\mathrm{XL})$ reactions are among the most powerful ways to control and improve the properties of polymeric materials, such as swelling and mechanical behavior [18-20]. However, the reticulation often relies on the introduction of cross-linker species, which requires special procedures, such as grafting by irradiation [21-24]. Furthermore, some crosslinker species might be attacked under the harsh conditions of an operating fuel cell.

[*] Corresponding Author, divona@uniroma2.it 
Thermal treatments of SAP membranes cast from dimethylsulfoxide (DMSO) in appropriate conditions improve their mechanical, thermal, and hydrolytic properties [25, 26]. For example thermally treated SPEEK membranes can resist in water also at $145^{\circ} \mathrm{C}$ without significant swelling, having a Young higher modulus than untreated SPEEK, with interesting proton conductivity [27-29]. These improved functional properties are of great interest in electrochemical applications (i.e., PEMFCs) and, according to our preliminary hypotheses, are related to the formation of covalent cross-links between macromolecular chains. Observing the structure of SPEEK, its functional groups, and considering the absence of a dedicated cross-linker species, we assume the formation of covalent bonds by an electrophilic aromatic substitution. This common reaction in organic chemistry can also occur on macromolecular chains, involving sulfonic acid groups that can act as electrophilic species under certain circumstances.

The electrophilic species assumed is the sulfonium ion $\mathrm{SO}_{2}^{+}$considering also some literature data about the existence of this species in acidic media [30]. The reaction of sulfonium ions could lead to the formation of a sulfone bridge linking two aromatic rings. In Scheme 1 are reported the postulated ways for the formation of XL SPEEK. We can recognize three possibilities: (i) the attack in an activated free position if the degree of sulfonation (DS) of the initial polymer is lower than 1 (pathway a); (ii) the attack in a deactivated ring in meta position to sulfonic or carbonylic groups (pathway $b$ ); or (iii) the attack of the electrophilic species in a position of the aromatic ring where a sulfonic group is already present (ipso substitution, pathway $c$ ). One can expect that the first reaction presents a lower activation energy than pathways $b$ and $c$.
In the following, we will demonstrate that this scheme is plausible and can account for the reported experimental results. The observed strong changes of mechanical properties and water uptake (WU) coefficients are of utmost importance for the development of new generation high performance SAPs to be used in technologically important applications.

The understanding of thermal treatments promoting crosslink reactions between adjacent polymer chains is the central objective of this work. Research for a better understanding of the mechanism of $\mathrm{XL}$ reactions is also a way to optimize thermal and hydrothermal treatments to achieve the best hydrolytic stability, mechanical and thermal properties, permeability, and ion conductivity for SPEEK.

\section{Experimental Section}

\subsection{Poly(ether ether ketone) (PEEK) Sulfonation}

SPEEK was prepared by reaction of PEEK (Victrex 450P, $\mathrm{MW}=38,300,132$ repeat units per mole) with concentrated sulfuric acid (95-98\%) under $\mathrm{N}_{2}$ at $50{ }^{\circ} \mathrm{C}$ for $2-4$ days in order to obtain a large DS (in the range $0.8-1$ ). The solution was poured, under continuous stirring, into an excess of ice-cold water obtaining a white precipitate [31]. After resting overnight, the precipitate was filtered and washed with water several times using a dialysis membrane (Sigma-Aldrich D9402) to neutral $\mathrm{pH}$ in order to eliminate completely the residual sulfuric acid. The sulfonated polymer (SPEEK) was then dried over night at $80^{\circ} \mathrm{C}$.
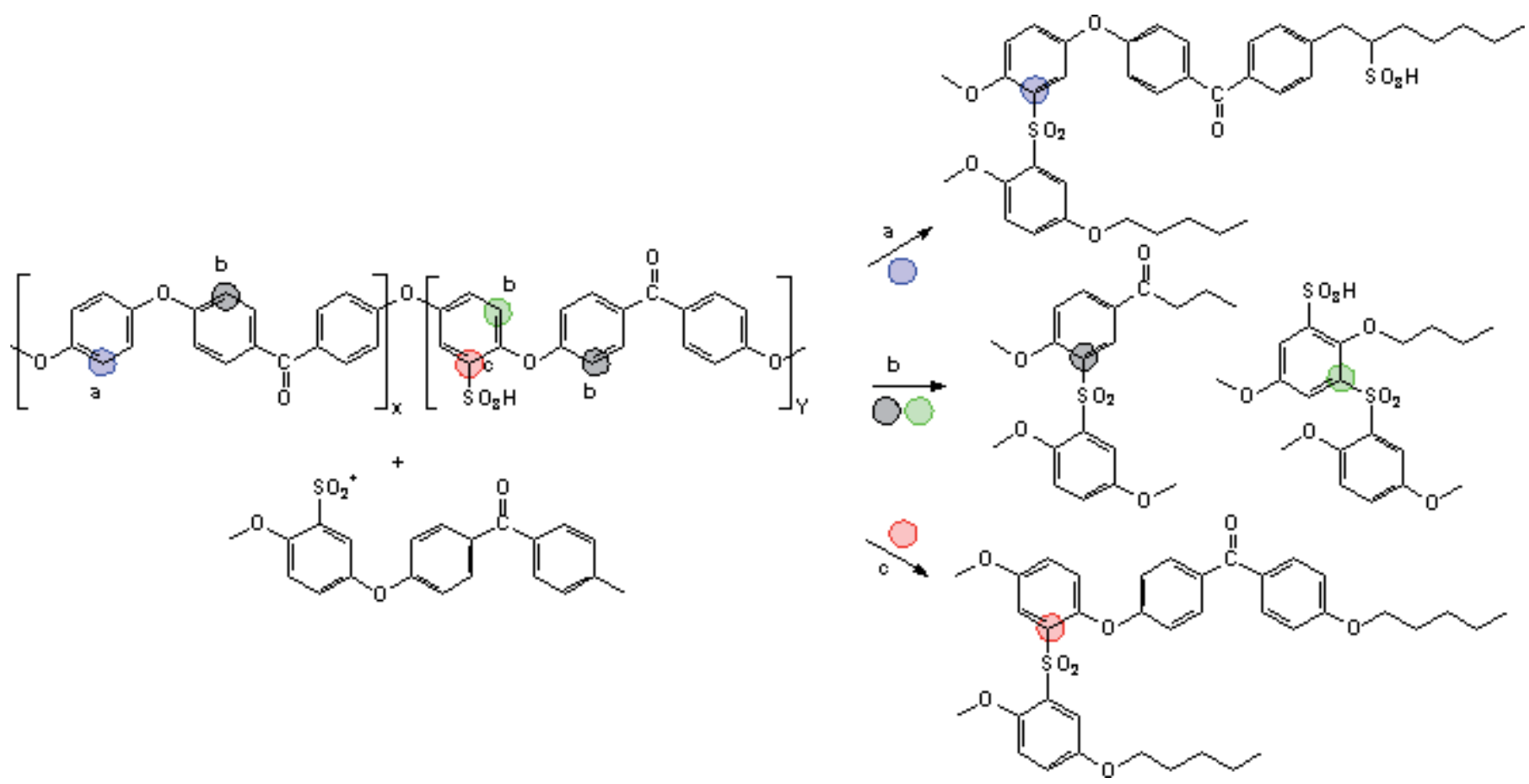

Scheme 1 Formation of cross-linked polymers. 


\subsection{Membrane Preparation}

In a typical experiment $200 \mathrm{mg}$ SPEEK was dissolved in $6 \mathrm{~mL}$ of DMSO, used as casting solvent at $80-90^{\circ} \mathrm{C}$. The resulting solution was evaporated under continuous stirring to 3-4 $\mathrm{mL}$, cast onto a Petri dish and dried in the oven for $24 \mathrm{~h}$ at a fixed temperature, chosen between 80 and $150{ }^{\circ} \mathrm{C}$. After cooling to room temperature, the resulting membranes were peeled off (in the following called "first treatment").

Membranes treated at $120^{\circ} \mathrm{C}$ have been submitted to a second thermal treatment, performed at $180^{\circ} \mathrm{C}$ for different time from 2 to $33 \mathrm{~h}$ (from here on referred to as "second treatment"). To evaluate the weight loss during thermal treatments, the membranes were dried on $\mathrm{P}_{2} \mathrm{O}_{5}$ and weighed before and after the thermal treatment.

\subsection{Characterization of SPEEK Membranes}

\subsubsection{Ion Exchange Capacity (IEC) Measurements}

The DS was evaluated both by ${ }^{1} \mathrm{H}$ NMR spectroscopy and by titration [32]. Both methods gave according values of DS/, where DS/ is the DS of the membrane after first treatment; in the following DS represents the DS after the second treatment. The IEC (in milliequivalents of sulfonic groups per gram of dry polymer) was determined by titration using the following procedure: a dry membrane in the acid form was converted to the sodium form by immersing the membranes in a $1.5 \mathrm{~N} \mathrm{NaCl}$ solution under stirring at room temperature for one night to exchange the $\mathrm{H}^{+}$ions with $\mathrm{Na}^{+}$ions, as shown previously [2]. The exchanged $\mathrm{H}^{+}$ions within the solutions were titrated with a $0.02 \mathrm{~N} \mathrm{NaOH}$ solution. The $\mathrm{pH}$ was recorded potentiometrically to determine the equivalence point. It was possible to estimate DS from IEC according to the relationship:

$\mathrm{DS}=\frac{\mathrm{IEC} \cdot M(\text { R.U. }) \times 10^{-3}}{1-\mathrm{IEC} \cdot M\left(\mathrm{SO}_{3} \mathrm{H}\right) \times 10^{-3}}$

where $M(R . U$.) is the molar mass of the polymer repeat unit (288 $\mathrm{g} \mathrm{mol}^{-1}$ for PEEK) and $M\left(\mathrm{SO}_{3} \mathrm{H}\right)$ is the molar mass of the sulfonic acid group.

In order to eliminate DMSO and its decomposition products, which can affect IEC, membranes were swelled in water at $100{ }^{\circ} \mathrm{C}$ for $5 \mathrm{~h}$. This procedure was insufficient to remove byproducts; therefore, after swelling in water at $100{ }^{\circ} \mathrm{C}$ for $5 \mathrm{~h}$, the samples were treated with $\mathrm{H}_{2} \mathrm{SO}_{4} 5 \mathrm{M}$ at room temperature for $2 \mathrm{~h}$ and then washed until neutral $\mathrm{pH}$ before the titration.

\subsubsection{High-Resolution Thermogravimetry}

High resolution thermogravimetric analyses (TGAs Q500, TA Instruments) were carried out between 25 and $600{ }^{\circ} \mathrm{C}$ with a maximum heating rate of $5{ }^{\circ} \mathrm{C} \mathrm{min}-1$ under air flux in platinum crucibles; generally, $7 \mathrm{mg}$ of sample were used. TGA was shown to be complementary to acid-base titration for determination of DS [33]. The number of sulfonic acid groups can be calculated as:
$n\left(\mathrm{SO}_{3} \mathrm{H}\right)=\frac{m\left(T_{1}\right)-m\left(T_{2}\right)}{M\left(\mathrm{SO}_{3} \mathrm{H}\right)}$

where $m\left(T_{1}\right)$ and $m\left(T_{2}\right)$ are sample masses at initial and final temperature of the peak corresponding to desulfonation, giving then IEC and DS. The decomposition of sulfonic acid groups was ascertained by on line mass spectrometry [33].

\subsubsection{Structural Characterization: FTIR}

FTIR spectra of membrane samples were collected in transmission mode in the range of 4,000-400 $\mathrm{cm}^{-1}$ (32 scans, $2 \mathrm{~cm}^{-1}$ resolution) with a Bruker Equinox 55. A background spectrum was run, and sample spectra were normalized against the background spectrum.

\subsubsection{Water Uptake of Membranes}

WU and WU coefficients $(\lambda)$ can be calculated according to the equations:

$$
\begin{aligned}
& \mathrm{WU}(\%)=\frac{m(\text { wet })-m(\text { dry })}{m(\text { dry })} \times 100 \\
& \lambda=\frac{N\left(\mathrm{H}_{2} \mathrm{O}\right)}{N\left(\mathrm{SO}_{3} \mathrm{H}\right)}=\frac{\mathrm{WU}(\%)}{\mathrm{IEC} \cdot M\left(\mathrm{H}_{2} \mathrm{O}\right)} \times 10
\end{aligned}
$$

where $m$ (dry) and $m$ (wet) are the masses of the polymer membrane before and after immersion in water. The samples were swelled in deionized water and treated with $\mathrm{H}_{2} \mathrm{SO}_{4}$ to remove residual DMSO and its decomposition products. After swelling, the samples were dried on $\mathrm{P}_{2} \mathrm{O}_{5}$ and weighed until steady state. The membranes were then immersed in deionized water contained in Teflon vessels of suitable thickness [13]. The vessels were hermetically closed and placed inside a temperature-controlled oven. Immersion time was $24 \mathrm{~h}$ at $100{ }^{\circ} \mathrm{C}$; after $24 \mathrm{~h}$, the membranes were left to stabilize in water at room temperature for $1 \mathrm{~h}$. The samples were recovered and the excess of external liquid water was removed by filter paper. The samples were immediately placed in a closed glass container and weighed.

\subsubsection{NMR Spectroscopy Measurements}

NMR spectra were recorded with a Bruker 300 instrument. To study DMSO decomposition products two series of ${ }^{1} \mathrm{H}$ NMR measurements were performed: (i) on a solution of DMSO and sulfuric acid and (ii) on thermally treated membranes. All thermal treatments were performed in a hermetically closed thick Teflon vessel; the samples were cooled to room temperature and then analyzed.

(i) A solution of DMSO and sulfuric acid (5\%) with deuterated water $\mathrm{D}_{2} \mathrm{O}$ was heated at $140{ }^{\circ} \mathrm{C}$ for $24 \mathrm{~h}$. Another solution with the same composition was heated at $120^{\circ} \mathrm{C}$ for $24 \mathrm{~h}$ and $180^{\circ} \mathrm{C}$ for $24 \mathrm{~h}$, to simulate the membrane treatment conditions.

(ii) A membrane treated at $140{ }^{\circ} \mathrm{C}$ was immersed in deuterated water at $100{ }^{\circ} \mathrm{C}$ for $24 \mathrm{~h}$. After this time the polymer 
was dissolved in water and the solution was analyzed. Another membrane heated at $120{ }^{\circ} \mathrm{C}$ for $24 \mathrm{~h}$ and $180{ }^{\circ} \mathrm{C}$ for $24 \mathrm{~h}$ was immersed in $\mathrm{D}_{2} \mathrm{O}$ at $100{ }^{\circ} \mathrm{C}$ for $24 \mathrm{~h}$. The membrane was insoluble in water this time; the $\mathrm{D}_{2} \mathrm{O}$ solution was sampled and analyzed.

The same solutions were also analyzed by GC-MS spectrometry using an HP 5890 series II gas chromatograph interfaced to an HP 5971 quadrupole mass detector.

\subsubsection{Measurement of the Quantity of Residual DMSO in the Polymer Matrix}

In this experiment $0.8 \mathrm{~g}$ of anhydrous PEEK powder (DS $=0.9$ ) was dissolved in $3.5 \mathrm{~g}$ of DMSO (corresponding to $\left.\lambda_{\text {DMSO }}=22\right)$ at $80^{\circ} \mathrm{C}$ in a weighing bottle. $\lambda_{\text {DMSO }}$ are the moles of DMSO per sulfonic group. After $24 \mathrm{~h}$ at $50{ }^{\circ} \mathrm{C}$ and $2 \mathrm{~h}$ at room temperature, the resulting solution was weighed (start point). The sample was opened and put into an oven at different temperatures (100, 120, 140, 150, and $\left.160^{\circ} \mathrm{C}\right)$. After various treatment time, up to $400 \mathrm{~h}$, the samples were weighed again to determine the kinetics of the weight loss and $\lambda_{\mathrm{DMSO}}$ values in the polymer matrix.

\section{Results and Discussion}

We will discuss now the experimental results in view of the cross-link reaction pathways postulated by us (Scheme 1) and we will answer some relevant questions about this process.

\subsection{How Can We Evidence the Presence of Cross-Linked Polymers via a Sulfone Bridge? How Can We Quantify XL?}

FTIR spectra of thermally treated ionomers show the presence of sulfonic groups and sulfone moieties linked to aromatic rings [25], while there is not evidence of the formation of condensation products between sulfonic acid groups (cf. sulfonic anhydride). This latter point will be discussed in some detail later. This is consistent with the postulated Scheme 1, but it does not allow quantification of the amount of XL.

A significant step forward can be achieved by elemental analysis combined with IEC determination. SPEEK membranes with DS $=1.0$ (obtained by titration and elemental analysis from total sulfur) were thermally treated at $180{ }^{\circ} \mathrm{C}$ for $15 \mathrm{~h}$. DMSO and all impurities due to the decomposition of DMSO were eliminated as described in the experimental part. After this treatment, the titration gives $\mathrm{DS}=0.6$, that is $0.6 \mathrm{~mol}$ of sulfonic groups per repeat unit. From this value it is possible to calculate the expected $\mathrm{S} / \mathrm{C}$ ratio per repeat unit, in this case $\mathrm{S} / \mathrm{C}=0.084$. Elemental analysis gave instead a ratio
$\mathrm{S} / \mathrm{C}=0.133$, which would correspond to a DS of 0.95 .

While the titration provides only the quantity of sulfonic acid groups, the elemental analysis measures the total sulfur present in the polymer. Consequently, the difference of the quantity of $S$ in the two measurements is the proof of the presence of different types of sulfur (Figure 1).

Combining elemental analysis and FTIR, it is possible to conclude that sulfone linkages are responsible of covalent XL that occurs by transformation of sulfonic acid groups. It is also possible to estimate for this membrane the degree of $\mathrm{XL}$ by $\mathrm{SO}_{2}$ bridges:

$\mathrm{XL}=(0.95-0.6) / 0.95=0.37$, i.e., $37 \%$ of cross-link bridges in this sample.

Furthermore, the difference between DS $=1.0$ and the apparent DS $=0.95$ by elemental analysis shows that $5 \%$ of sulfonic groups have been eliminated. Considering Scheme 1, this loss of $\mathrm{SO}_{3} \mathrm{H}$ groups corresponds to the ipso-substitution pathway. This means that about $10 \%$ of cross-links are formed in ipso-position.

\subsection{Is DMSO Indispensable to Achieve XL? What Is the Role of DMSO}

We have verified previously that membranes cast from dimethylacetamide, $N$-methyl-2-pyrrolidone, acetone, and acetone/water did not undergo XL [25]. These membranes, whatever the temperature of the thermal treatment, showed identical NMR and FTIR spectra before and after treatment, unchanged IEC, and the same elemental analysis. We concluded that DMSO was essential for the XL.

DMSO has a tetrahedral structure with sulfur, oxygen, and carbon atoms at the corners. Its properties have been studied extensively in the relevant literature since it is used in many applications ranging from medicine to organic synthesis [34]. DMSO is a polar aprotic solvent with a tendency to accept protons higher than water or alcohols, and with lower toxicity than other members of this class, such as dimethylformamide, dimethylacetamide, $N$-methyl-2-pyrrolidone, and hexamethyl-phosphoramide.

It is highly associated with an ordered structure and a high dielectric constant $(\varepsilon=46.7)$ due to the quite polar sulfuroxygen bond, so that it has strong interactions with solutes which are strong hydrogen-bond donors [35]. For this reason, it is considered as a very good solvent and can form stable solvates by dipole-dipole interactions or solvent-solute associations. The chemistry of polar aprotic solvents is very differ-

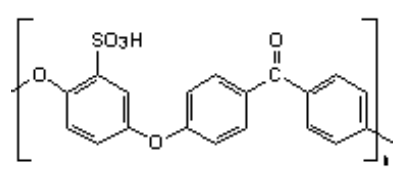

Initial sample

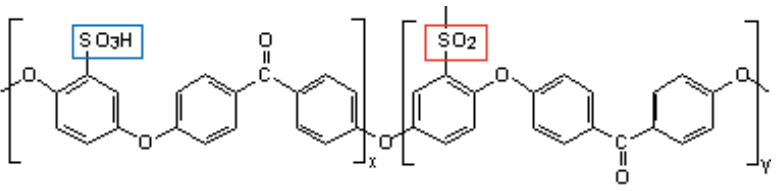

Sample after cross-link
Fig. 1 Repeat unit of SPEEK with DS = 1 (left) and repeat units containing sulfonic groups ( $x=\mathrm{DS})$ and sulfone bridges ( $y=$ degree of cross-link, $\mathrm{XL}$, right). 
ent from that of water, e.g., anions are much less solvated in these solvents [36], and because of the superior electron density at the oxygen atom and the steric accessibility of the oxygen, DMSO solvates cations in general [37]. The fact that DMSO possesses at the same time appreciable nucleophilic properties (donor number, $\mathrm{DN}=29.8$ ) and electrophilic properties (acceptor number, $\mathrm{AN}=19.3$ ) accounts for its increasing use in basic research and industry [38, 39]. It is also known that pure DMSO is thermally stable. Its decomposition temperature is above $190{ }^{\circ} \mathrm{C}$, but in presence of some agents self-accelerated exothermic decompositions can occur at lower temperatures. In presence of acids, e.g., with $\mathrm{H}_{2} \mathrm{SO}_{4}$ $36 \mathrm{~N}$ at $125{ }^{\circ} \mathrm{C}, 14 \%$ decomposition has been reported with formation of $\mathrm{CH}_{3} \mathrm{SCH}_{3}, \mathrm{CH}_{3} \mathrm{SSCH}_{3}$, and other minor products [40].

In cross-link reactions, DMSO can play mainly two roles:

(i) reactant (DMSO as such or its decomposition products)

(ii) catalyst (including solvent effects)

To understand if the XL reaction is due to decomposition products, given that DMSO is in acidic medium in the membrane, we compared the products released from DMSO inside the acidic membrane with decomposition products formed by DMSO and sulfuric acid alone. The products were monitored by ${ }^{1} \mathrm{H}$ and ${ }^{13} \mathrm{C}$ NMR spectroscopy after thermal treatment and, in the case of membranes, swelling in deuterated water at $100{ }^{\circ} \mathrm{C}$. Table 1 shows in the first column the results obtained analyzing the spectra of DMSO treated in the presence of $\mathrm{H}_{2} \mathrm{SO}_{4}$ for $24 \mathrm{~h}$ at $140{ }^{\circ} \mathrm{C}$, where $\mathrm{XL}$ is not observed, and diluted with $\mathrm{D}_{2} \mathrm{O}$.

The second column shows results obtained analyzing deuterated water, where the SPEEK membrane was swelled after thermal treatment at the same temperature for the same time.

Table 2 shows in the first column results obtained analyzing the spectra of DMSO treated in the presence of $\mathrm{H}_{2} \mathrm{SO}_{4}$ for $24 \mathrm{~h}$ at $120{ }^{\circ} \mathrm{C}$ and $24 \mathrm{~h}$ at $180{ }^{\circ} \mathrm{C}$. In the second column are results obtained analyzing deuterated water where the SPEEK membrane (cast from DMSO) was swelled after thermal treatment at the same temperature for the same time;

Table 1 Products released by DMSO under different conditions at $140^{\circ} \mathrm{C}$.

${ }^{1} \mathrm{H} \mathrm{DMSO}+\mathrm{H}_{2} \mathrm{SO}_{4}+\mathrm{D}_{2} \mathrm{O} 140{ }^{\circ} \mathrm{C}(24 \mathrm{~h})$

$\mathrm{CH}_{3} \mathrm{SSCH}_{3}(3 \%)$

$\mathrm{CH}_{3} \mathrm{SCH}_{3}(2 \%)$

Probably $\mathrm{CH}_{3} \mathrm{SCH}_{2} \mathrm{CH}_{2} \mathrm{SCH}_{3}$ via GC/MS (2\%)

$\mathrm{CH}_{3} \mathrm{SO}_{3} \mathrm{H}$ (traces) here $\mathrm{XL}$ is observed. In a closed vessel under nitrogen, oxidized products, such as dimethyl sulfone, are not observed.

The good agreement among two sets of measurements indicates that the formation of the decomposition products is independent of the presence of the polymer matrix; consequently one can also suppose that the reticulation is not due to decomposition products.

It was also reported in the literature that DMSO strongly interacts with sulfonic groups of benzenesulfonic acid, which can be considered a good model for SPEEK membranes [41] with a maximum of 2.5-3 molecules of DMSO per sulfonic acid group.

To confirm these data, we studied the interaction between DMSO and SPEEK at different temperatures, measuring the quantity of residual DMSO in the polymer matrix (Figure 2).

We can observe that after a treatment, e.g., at $120{ }^{\circ} \mathrm{C}$ for $50 \mathrm{~h}$, there are around $1.5 \mathrm{~mol}$ of DMSO per sulfonic acid group. The DMSO is completely removed only after about

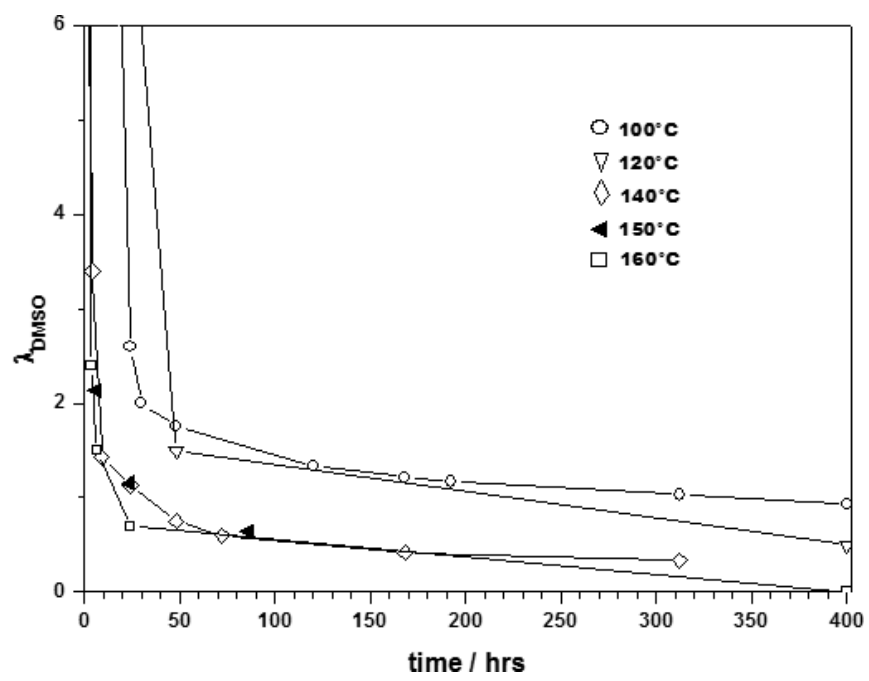

Fig. $2 \lambda_{\mathrm{DMSO}}$ as function of time of treatment at different temperatures after that a known quantity of DMSO was added to SPEEK powder (DS $=0.9$ ). Solid lines are given as guides to the eye.

${ }^{1} \mathrm{H}$ SPEEK $140{ }^{\circ} \mathrm{C} 24 \mathrm{~h}+$ swelling $100{ }^{\circ} \mathrm{C} \mathrm{D}_{2} \mathrm{O}(24 \mathrm{~h})$

$\mathrm{CH}_{3} \mathrm{SSCH}_{3}(2 \%)$

$\mathrm{CH}_{3} \mathrm{SCH}_{3}(1 \%)$

Probably $\mathrm{CH}_{3} \mathrm{SCH}_{2} \mathrm{CH}_{2} \mathrm{SCH}_{3}$ via GC/MS (2\%)

$\mathrm{CH}_{3} \mathrm{SO}_{3} \mathrm{H}$ (traces)

Probably $\mathrm{HSO}_{3}-\mathrm{OCH}_{3}$ (traces via GC/MS)

Table 2 Products released by DMSO under different conditions at $120^{\circ} \mathrm{C} 24 \mathrm{~h}+180{ }^{\circ} \mathrm{C} 24 \mathrm{~h}$.

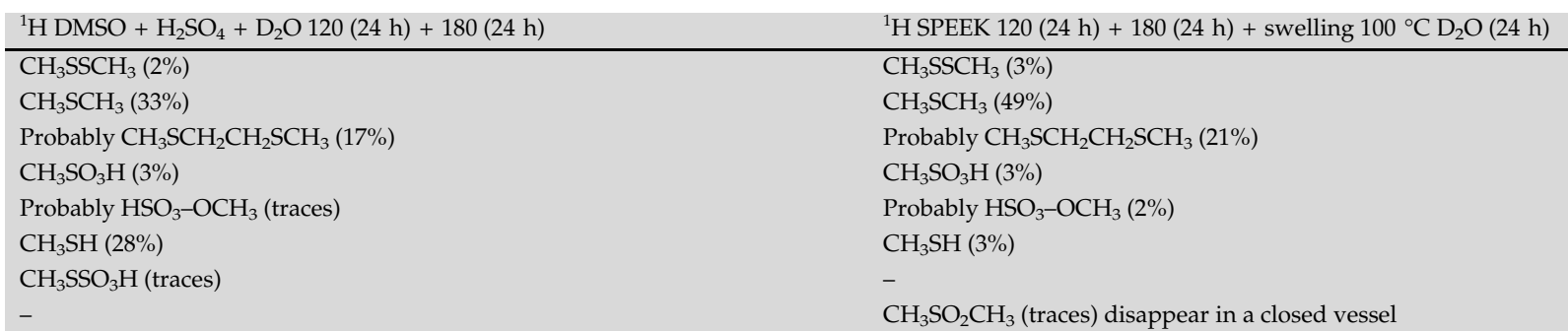


$400 \mathrm{~h}$ at $160{ }^{\circ} \mathrm{C}$. The nature of the interaction between $\mathrm{SO}_{3} \mathrm{H}$ moieties and the solvent is due to strong hydrogen bonds and dipole-dipole interactions as drawn in Scheme 2a.

The interaction can evolve into an ion pair, which in turn can lead to an intermediate and finally to the electrophilic species (Scheme $2 \mathrm{~b}$ ). The electrophilic species are supposed to start the cross-link reaction, as in Scheme 1.

Another possibility for the preparation of aryl sulfones by heating aryl sulfonic acid in the presence of aryl compounds was reported long time ago [42] and reviewed in the following years [43]. It was postulated that this reaction occurs via the formation of aromatic sulfonic anhydrides that evolve to the electrophilic species by heat treatment [44]. The anhydride was several times reported to be present in polymer electrolyte membranes like Nafion [45]. The formation of the anhydride should be favored by the presence of DMSO that enhances the anion reactivity (Scheme 2c). The anhydride does not resist long treatments in liquid water [46] especially in the presence of an acid catalyst wherein the hydrolysis reaction take places, as recently shown by Gebel and coworkers [47]. In our conditions, that is swelling in water at $100{ }^{\circ} \mathrm{C}$ for $5 \mathrm{~h}$ in acidic medium (the lower DS for XL membranes is around 0.4) and immersion in $\mathrm{H}_{2} \mathrm{SO}_{4} 5 \mathrm{M}$ for $2 \mathrm{~h}$, the anhydride, if present, should be hydrolyzed to sulfonic acid. The FTIR analysis (see \$3.3 Figure 6b) confirms this point. Furthermore, we conducted recently an $\mathrm{XL}$ reaction on $p$ toluenesulfonic acid chosen as model compound [25]. The reaction products analyzed by NMR and gas chromatogra-

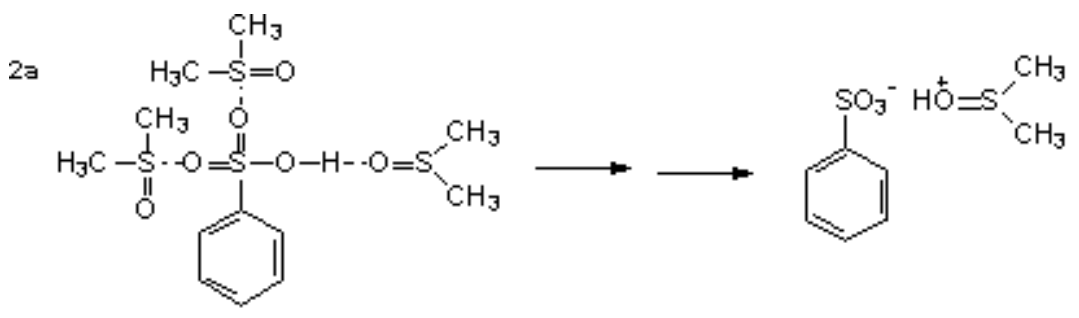

$2 \mathrm{~b}$<smiles>CC(C)[C@H](O)[C@H](C)OS(C)(C)OS(=O)(=O)c1ccccc1</smiles>

20<smiles>O=S(=O)([O-])c1ccccc1</smiles>

Scheme 2 Interaction between DMSO and benzenesulfonic acid taken as a model compound. $2 a)$ Formation of an ion pair and $2 b$ ) of the electrophilic species. 2c) Formation of the sulfone bridge via an anhydride. phy-mass spectrometry did not contain any trace of stable anhydride.

However, the occurrence of sulfonic anhydrides as intermediate in the cross-link reaction cannot be excluded and it can be competitive especially when activated free positions are absent in the starting polymer (DS =1).

From this analysis, it is quite clear that DMSO can promote the formation of the electrophilic $-\mathrm{SO}_{2}^{+}$intermediate both through the formation of a direct interaction with the solvent or by the formation of an anhydride moiety. As a consequence, it is not surprising that a polar aprotic solvent, like DMSO, can have a dramatic influence on the reaction [48].

\subsection{What Are the Best Treatments to Achieve the Major Quantity of $X L$ with the Minor Effort?}

Important aspects of membrane development are the cost and ecological impact of the performed treatments, including temperature, time, and nature of solvent as relevant parameters.

Fundamental is the use of DMSO in the casting procedure and the presence of its residue in the formed membranes subject to thermal treatments. The cross-link reaction occurs only on membranes cast from DMSO at temperatures higher than $150{ }^{\circ} \mathrm{C}$. Membranes treated in DMSO at a temperature lower than $150{ }^{\circ} \mathrm{C}$ show unchanged properties [25].

Many experiments were carried out to achieve the best condition for XL. It was observed that if the casting procedure is conducted directly at a temperature greater than $150{ }^{\circ} \mathrm{C}$, e.g., in the range 160 $180^{\circ} \mathrm{C}$, the quantity of sulfone bridges is generally low with scarce reproducibility.

A two-step thermal treatment is necessary to perform a successful XL process: the first step is an evaporation treatment that leaves the "optimal" quantity of residual DMSO inside the membrane and probably optimizes the chain conformation for facilitating the XL reaction. The second step is the effective treatment that allows running the $\mathrm{XL}$ reaction in the presence of a suitable amount of residual DMSO.

To optimize the first treatment we have studied XL degree as a function of the first treatment temperature. The second treatment, in this analysis, was always $180{ }^{\circ} \mathrm{C}$ for $24 \mathrm{~h}$. Figure 3 shows XL degree as a function of the temperature of the first treatment performed for $24 \mathrm{~h}$ for a sample with DS $=0.81$. We can observe that if the temperature is too low, the quantity of XL is low. We infer that too much DMSO separates the macromolecular chains and does not permit the achievement of the right conformation. Important cross-link is observed, when the first treatment is performed at $120^{\circ} \mathrm{C}$. For 
higher temperatures $\mathrm{XL}$ decreases, probably because there is not enough DMSO left inside the polymeric membrane.

From these data, it is possible to conclude that the amount of DMSO in the membrane is a crucial factor that controls the successive XL reaction and, under our experimental conditions, the best temperature for the first treatment is $120{ }^{\circ} \mathrm{C}$.

The time for the second treatment was optimized studying the change in DS for a sample with IEC $=2.5 \mathrm{meq} \mathrm{g}^{-1}$ (DS $=0.9$ ) as a function of time of the second treatment, which was performed at $180{ }^{\circ} \mathrm{C}$, i.e., at a temperature suitable for the XL between polymer chains.

This temperature was selected to achieve relatively short times of treatment. In fact, when the reaction is carried out at $160{ }^{\circ} \mathrm{C}$ sufficiently large amount of $\mathrm{XL}$ is obtained only for times around $64 \mathrm{~h}$, while a temperature higher than $180{ }^{\circ} \mathrm{C}$ can lead to desulfonation reactions. Therefore, it is important to find the best compromise between time and temperature of treatment in order to facilitate the industrial scale-up.

The degree of $\mathrm{XL}$ is expected to increase with treatment time, accompanied by a decrease of DS, given that XL reaction involves sulfonic acid groups (see Section 3.1).

Figure 4 shows the results of titration (red line) performed on treated membranes after swelling in water at $100{ }^{\circ} \mathrm{C}$. It is rather surprising to note that almost the same value of DS and IEC was obtained for all samples in the range $2-33 \mathrm{~h}$. In

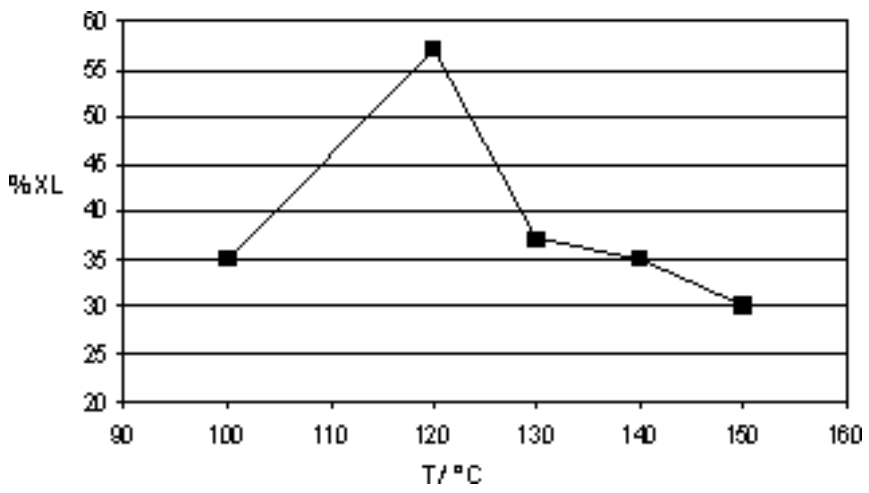

Fig. 3 Quantity of cross-link as a function of the first treatment temperature. The solid line is a guide to the eye.

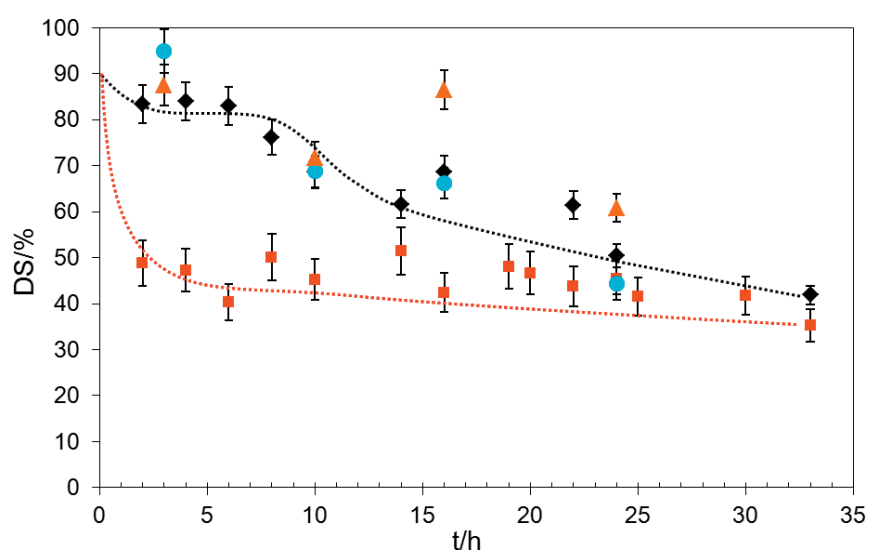

Fig. 4 DS as a function of the time of second treatment at $180^{\circ} \mathrm{C}$. By titration: before regeneration; after regeneration. By TGA: acid-form; $\Delta$ sodium-form. Red and black dotted lines are given as guides to the eye. fact, this result would imply that the XL reaction is very fast, reaching completion within a couple of hours. However, these membranes show a very different hydrolytic behavior although the IEC value is apparently the same. These arguments suggest that the results are affected by some systematic errors.

As discussed previously, DMSO is able to interact strongly with sulfonic groups and we hypothesized that the trend we measured by titration of as-swelled membranes was probably affected by strong interactions between sulfonic groups and DMSO. In other words, most $-\mathrm{SO}_{3} \mathrm{H}$ groups were shielded in some way by DMSO molecules and not available to ionexchange, thus inducing an underestimation of DS by potentiometric titration. Therefore, a second measurement was carried out to check this hypothesis: the membranes were washed in $\mathrm{H}_{2} \mathrm{SO}_{4} 5 \mathrm{M}$ for $2 \mathrm{~h}$, washed again with water and then subjected to the titration procedure. This process was called "regeneration". After regeneration, the black curve of Figure 4 was obtained. This different behavior confirms that the strong interactions between $-\mathrm{SO}_{3} \mathrm{H}$ and DMSO were most likely responsible of the DS trend obtained after the first series of titration data and that in the first titration not all sulfonic groups could exchange protons. This interaction between $-\mathrm{SO}_{3} \mathrm{H}$ and DMSO is not destroyed by swelling in hot water but only in strong acid environment, where $\mathrm{H}_{2} \mathrm{SO}_{4}$ is able to wash residual DMSO out.

Figure 5 shows typical thermogravimetric measurements made on SPEEK membranes with first ("untreated") and second treatment at $180{ }^{\circ} \mathrm{C}$ for 3,10 , and $24 \mathrm{~h}$.

The peaks around 250 and $450{ }^{\circ} \mathrm{C}$ can be attributed by coupling with mass spectrometry to decomposition of sulfonic acid groups and main chain of the polymer, respectively. Sulfone bridges are decomposed together with the main chain, as shown previously [26]. The amount of sulfonic acid groups decreases with time, as can be easily seen from the integrated mass loss. The results, shown in Figure 4, are in good agreement with those obtained by titration after regeneration. The TGA analysis is thus consistent with the WU and IEC data.

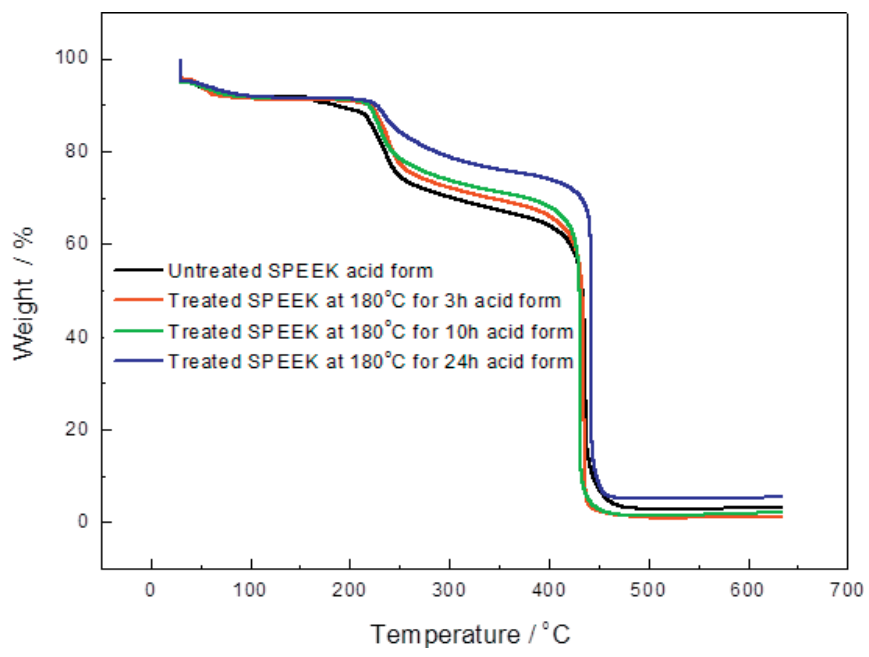

Fig. 5 TGA analysis of SPEEK DS $/=0.9$ with second treatment at $180^{\circ} \mathrm{C}$ for different times. 
Two membranes treated at $180{ }^{\circ} \mathrm{C}$ for $10 \mathrm{~h}$ were analyzed before and after swelling in water by FTIR spectroscopy to check the presence of esters or anhydrides as discussed in \$3.1 (Figure 6). In the spectra, it is possible to identify typical absorption peaks of PEEK [49] and sulfonic groups [50]: the signal at $1,650 \mathrm{~cm}^{-1}$ is attributed to the stretching vibration of carbonyl group, while the peak at $1,597 \mathrm{~cm}^{-1}$ corresponds to skeletal in-plane vibration of phenyl rings. Sulfonic groups are mainly characterized by two bands in the range at 1,080 and $1,021 \mathrm{~cm}^{-1}$, attributed to asymmetric and symmetric $\mathrm{SO}_{2}$ stretching. Signals due to 1:2:4-substituted phenyl rings are present at 1,279 and $1,225 \mathrm{~cm}^{-1}$ while $\mathrm{S}=\mathrm{O}$ stretching vibration of $\mathrm{PhSO}_{2} \mathrm{Ph}$ is present at $1,165 \mathrm{~cm}^{-1}$. In the frequency region corresponding to hydrogen bond vibrations, apart from a broad band at $3,400 \mathrm{~cm}^{-1}$ from water absorbed, peaks due to methyl groups, belonging to DMSO and derivatives, are observed in the spectrum before the regeneration. The lack in both spectra of a peak at $1,440 \mathrm{~cm}^{-1}$, typical of condensation products $[25,45]$, indicates the absence in the final material of sulfonic anhydrides (Figure 6b). The characteristic vibrations are reported in Table 3.
Table 3 Characteristic vibrations for the sample treated at $180^{\circ} \mathrm{C}$ for $10 \mathrm{~h}$ before regeneration.

\begin{tabular}{ll} 
Wave number $\left(\mathrm{cm}^{-1}\right)$ & Characteristic vibrations \\
\hline $3,400(\mathrm{~s}$, broad) & Stretching of $\mathrm{O}-\mathrm{H}$ \\
$2,910(\mathrm{w})$ & Symmetric stretching of $-\mathrm{CH}_{3}$ \\
$2,845(\mathrm{w})$ & Asymmetric stretching of $-\mathrm{CH}_{3}$ \\
$1,650(\mathrm{~m})$ & Symmetric stretching of $\mathrm{C}=\mathrm{O}$ \\
$1,597(\mathrm{~s})$ & Skeletal in-plane vibration of phenyl rings \\
$1,472(\mathrm{~s})$ & Symmetric stretching aromatic $\mathrm{C}-\mathrm{C}$ \\
$1,414-1,400(\mathrm{~m})$ & (split due to substitution upon sulfonation) \\
& Asymmetric stretching of $-\mathrm{SO}_{3} \mathrm{H}$ group \\
$1,252(\mathrm{~s})$ & Stretching of $1,2,4$-substituted phenyl rings \\
$1,225(\mathrm{~s})$ & \\
$1,279(\mathrm{shoulder})$ & Stretching of $\mathrm{S}=\mathrm{O}$ of $\mathrm{PhSO} \mathrm{Ph}^{\mathrm{Ph}}$ \\
$1,128(\mathrm{tail})$ & \\
$1,165(\mathrm{~s})$ & Symmetric stretching of $-\mathrm{SO}_{3} \mathrm{H}$ group \\
$1,080(\mathrm{~m})$ & Bending of $-\mathrm{SO}{ }_{3} \mathrm{H}$ group \\
$1,021(\mathrm{~m})$ &
\end{tabular}

\subsection{Can We Analyze the Reaction Pathways?}

From the data shown before, it is clear that sulfonic acid groups participate in the formation of sulfone bridges. The evaluation of the weight variation is important to understand the mechanism of the cross-link process. When the $\mathrm{XL}$ reaction occurs, a loss of water, or $\mathrm{H}_{2} \mathrm{SO}_{4}$ in the case of ipso substitution, should be observed. Figure 7 shows the weight loss and the DS by titration as a function of time at $180{ }^{\circ} \mathrm{C}$.

An initial weight loss of $3-5 \%$ was observed until $5 \mathrm{~h}$ of thermal treatment; then a strong decrease occurred up to a constant value of $\sim 15 \%$ after $35 \mathrm{~h}$ (corresponding to XL degree around 45\%). The larger loss occurring at longer time is related to the attack in a deactivated aromatic ring (Scheme $1 b$ ) and to loss of sulfonic moieties by ipso substitution (Scheme 1c) that require higher activation energy. The ipso substitution being around $10 \%$ of the total XL (see part 3.1) gives about $4.5 \%$ loss due to $\mathrm{H}_{2} \mathrm{SO}_{4}$ $\left(M=98 \mathrm{~g} \mathrm{~mol}^{-1}\right)$. The initial loss is due to the loss of residual solvents and loss of water due to "fast" cross-link in activated positions (Scheme 1a). The amount of activated rings is here $10 \%$ of the total (DS $=0.9$ ), means $1.8 \% \mathrm{H}_{2} \mathrm{O}\left(M=18 \mathrm{~g} \mathrm{~mol}^{-1}\right)$. In order to find the experimental value of around $4 \%$, a loss of solvents of about $2 \%$ is necessary. The remaining loss, around $30 \%$, is due to $\mathrm{XL}$ in deactivated positions with loss of $\mathrm{H}_{2} \mathrm{O}$, corresponding to $5.4 \%$. It is important to note that there is a good agreement between the second experimental loss $(10 \%)$ and the calculated weight loss.

The observed trend is similar to the variation of DS after regeneration. The accordance between two independent measurements,

Fig. 6 (a) FTIR spectra of samples before regeneration (blue line, 1) and after regeneration (green line, 2); (b) magnification of spectrum (a) in the typical region of the absorbance of sulfonic anhydrides. 


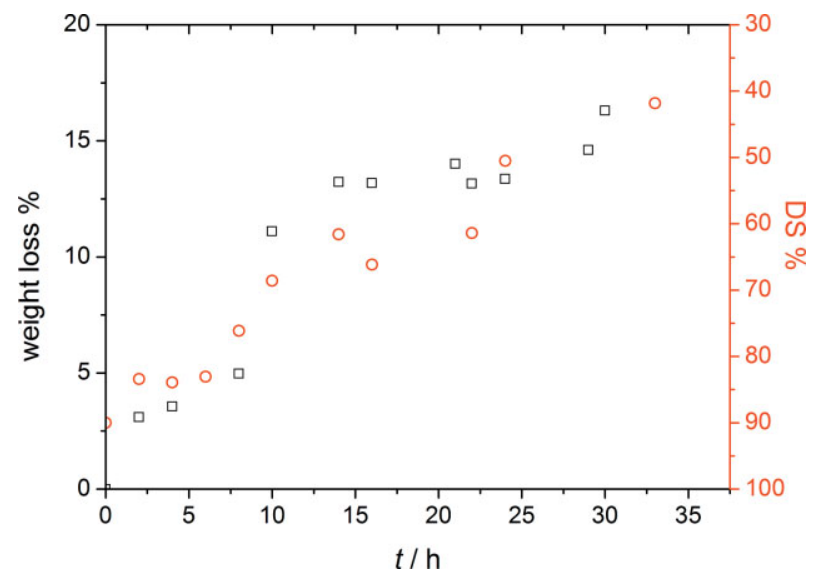

Fig. 7 Comparison of decreases of DS $(O)$ and weight loss $(\square)$ for the same sample.

weight loss and variation of DS, reported in Figure 7, can be justified considering that two energetically different processes, namely an "easy reaction" and a "difficult reaction" are possible. In a polymer with a DS $=0.9$ there are $10 \%$ of activated positions (see pathway $a$ of Scheme 1) that can undergo the electrophilic attack with faster reaction kinetics and slower reactions due to the attack in deactivated positions, as shown in Scheme 3. Therefore, the so-called "difficult reaction" occurs only when pathway $a$ is no more accessible and requires longer reaction times (i.e., more than 10-12 $\mathrm{h}$ under our experimental conditions) to reach completion.

\subsection{What is the Effect on Water Uptake?}

WU was measured on membranes treated at $180{ }^{\circ} \mathrm{C}$ for different times. Figure 8 shows a continuous drop of WU between 2 and $33 \mathrm{~h}$, with a steep decrease between 2 and $10 \mathrm{~h}$.

$\mathrm{WU}$, expressed as $\lambda$, is reported as function of IEC by titration in Figure 9.

We can observe that for $t<8 \mathrm{~h}$ and IEC $>2.2 \mathrm{meq} \mathrm{g}^{-1}$ the membranes have similar values of IEC (consistent with Figures 4 and 7), but very different values of $\lambda$, while for $t>8 \mathrm{~h}$ and IEC $<2.2 \mathrm{meq} \mathrm{g}^{-1}, \lambda$ decreases with decreasing IEC. The right side (black line) of the curve could be explained consid-<smiles>CCOc1ccc(C(=O)c2ccc(Oc3ccc(Oc4ccc(Oc5ccc(Oc6ccc(C(=O)c7ccc(Oc8ccc(OC)cc8)cc7)cc6)cc5O)cc4)cc3)cc2)cc1</smiles>

Scheme 3 Representation of two possible cross-link reactions with schematic of activation barriers.

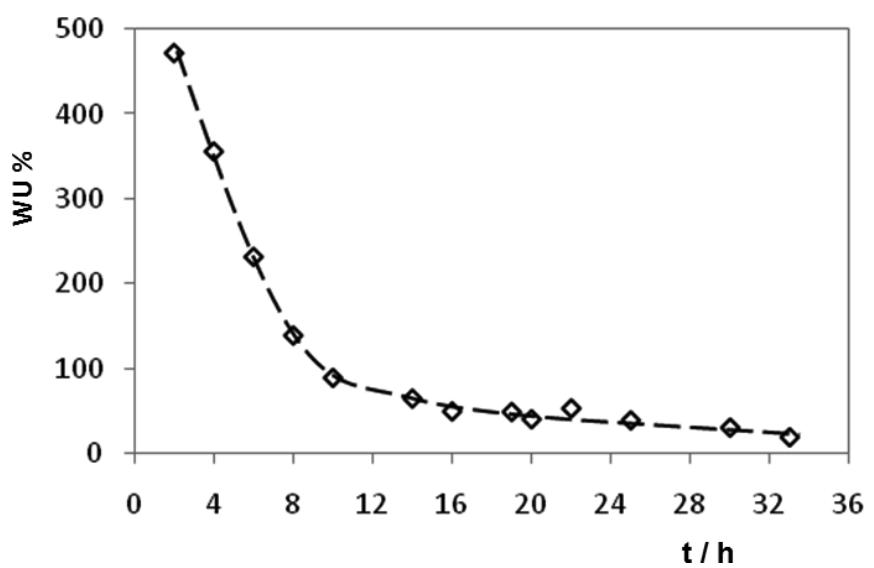

Fig. $8 \mathrm{WU}$ for immersion in liquid water at $100{ }^{\circ} \mathrm{C}$ during $24 \mathrm{~h}$ as function of time of second treatment at $180^{\circ} \mathrm{C}$. The dotted line is a guide to the eye.

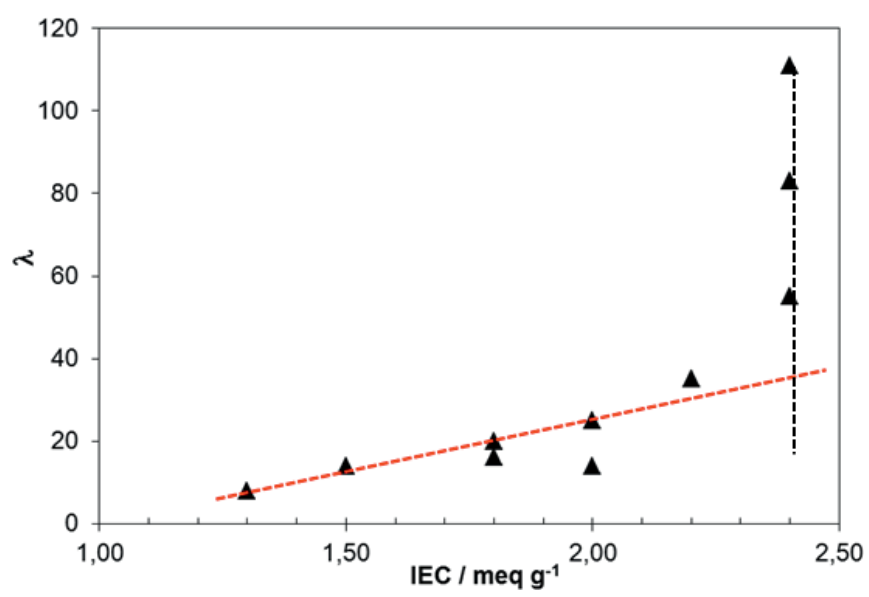

Fig. $9 \lambda$ as a function of IEC, measured by immersion in water at $100^{\circ} \mathrm{C}$ during $24 \mathrm{~h}$ for samples with $\mathrm{DS}=0.9$, treated at $180^{\circ} \mathrm{C}$ for different times.

ering also the effect of annealing in addition to small contribution of XL. In fact, it is known that annealing can decrease the free volume inside a membrane, leading to a membrane with improved mechanical properties and consequently less WU [51]. Although, this effect is not sufficient to stabilize membranes at high temperatures, it can explain the reduction of WU at large IEC values, as shown in Figure 9.

Furthermore, in this test all membranes do not dissolve at $100{ }^{\circ} \mathrm{C}$; it is worth stressing that even after $3 \mathrm{~h}$ of treatment at $180{ }^{\circ} \mathrm{C}$ the number of covalent bridges between macromolecular chains is large enough to modify deeply the hydrophilic properties of the sulfonated polymer, inhibiting its solubility in water.

\section{Conclusion}

In this work, we discussed and quantified the processes leading to covalent $\mathrm{XL}$ between macromolecular chains during heat treatments above $150{ }^{\circ} \mathrm{C}$ of SPEEK membranes in presence of small quantities of DMSO. Electrophilic aromatic substitution by sulfonium ions is possible in different posi- 
tions, activated positions in unsulfonated phenyl rings, deactivated meta-positions to sulfonic acid groups, and deactivated positions already occupied by sulfonic acid (ipso-substitution). The different activation energies lead to different reaction times, observed by studying the evolution of the DS using potentiometric titrations, WU measurements, and TGA. Similar mechanistic considerations can be made for other SAPs. The modification of properties (such as hydrothermal stability, mechanical properties,...) subsequent to $\mathrm{XL}$ are of utmost importance for membrane development used in various electrochemical techniques, such as fuel cells.

\section{Acknowledgements}

The EU-FP7 (FCH-JU) project "LoLiPEM - Long-life PEM$\mathrm{FCH} \& \mathrm{CHP}$ systems at temperatures higher than $100{ }^{\circ} \mathrm{C}^{\prime \prime}$ (GA 245339), is gratefully acknowledged for co-funding this work.

\section{References}

[1] P. D. Beattie, F. P. Orfino, V. I. Basura, K. Zychowska, J. F. Ding, C. Chuy, J. Schmeisser, S. Holdcroft, J. Electroanal. Chem. 2001, 503, 45.

[2] G. Alberti, M. Casciola, L. Massinelli, B. Bauer, J. Membr. Sci. 2001, 185, 73.

[3] R. Borup, J. Meyers, B. Pivovar, Y. S. Kim, R. Mukundan, N. Garland, D. Myers, M. Wilson, F. Garzon, D. Wood, P. Zelenay, K. More, K. Stroh, T. Zawodzinski, J. Boncella, J. E. McGrath, M. Inaba, K. Miyatake, M. Hori, K. Ota, Z. Ogumi, S. Miyata, A. Nishikata, Z. Siroma, Y. Uchimoto, K. Yasuda, K. I. Kimijima, N. Iwashita, Chem. Rev. 2007, 107, 3904.

[4] Q. F. Li, R. H. He, J. O. Jensen, N. J. Bjerrum, Chem. Mater. 2003, 15, 4896.

[5] B. Smitha, S. Sridhar, A. A. Khan, J. Membr. Sci. 2005, 259, 10.

[6] H. Y. Hou, M. L. Di Vona, P. Knauth, ChemSusChem 2011, 4, 1526.

[7] M. Rikukawa, K. Sanui, Prog. Polym. Sci. 2000, 25, 1463.

[8] J. Roziere, D. J. Jones, Ann. Rev. Mater. Res. 2003, 33, 503.

[9] J. A. Kerres, J. Membr. Sci. 2001, 185, 3.

[10] A. Carbone, R. Pedicini, G. Portale, A. Longo, L. D'Ilario, E. Passalacqua, J. Power Sources 2006, 163, 18.

[11] S. D. Mikhailenko, F. Celso, S. Kaliaguine, J. Membr. Sci. 2009, 345, 315.

[12] W. Schmittinger, A. Vahidi, J. Power Sources 2008, 180, 1.

[13] G. Alberti, R. Narducci, M. Sganappa, J. Power Sources 2008, 178, 575.

[14] M. Casciola, G. Alberti, M. Sganappa, R. Narducci, J. Power Sources 2006, 162, 141.

[15] L. Zhang, S. Mukerjee, J. Electrochem. Soc. 2006, 153, A1062.

[16] S. Kaliaguine, S. D. Mikhailenko, K. P. Wang, P. Xing, G. Robertson, M. Guiver, Catal. Today 2003, 82, 213.
[17] EU FP7 FCH-JU 2010 www.lolipem.eu.

[18] J. A. Kerres, Fuel Cells 2005, 5, 230.

[19] S. D. Mikhailenko, G. P. Robertson, M. D. Guiver, S. Kaliaguine, J. Membr. Sci. 2006, 285, 306.

[20] J. Chen, D. Li, H. Koshikawa, M. Asano, Y. Maekawa, J. Membr. Sci. 2010, 362, 488.

[21] X. W. Chen, B. Gholamkhass, X. Han, G. Vamvounis, S. Holdcroft, Macromol. Rapid Commun. 2007, 28, 1792.

[22] J. H. Chen, Y. Maekawa, M. Asano, M. Yoshida, Polymer 2007, 48, 6002.

[23] J. L. Zhang, Z. Xie, J. J. Zhang, Y. H. Tanga, C. J. Song, T. Navessin, Z. Q. Shi, D. T. Song, H. J. Wang, D. P. Wilkinson, Z. S. Liu, S. Holdcroft, J. Power Sources 2006, 160,872 .

[24] S. Hasegawa, S. Takahashi, H. Iwase, S. Koizumi, N. Morishita, K. Sato, T. Narita, M. Ohnuma, Y. Maekawa, Polymer 52, 98.

[25] M. L. Di Vona, E. Sgreccia, S. Licoccia, G. Alberti, L. Tortet, P. Knauth, J. Phys. Chem. B 2009, 113, 7505.

[26] M. L. Di Vona, E. Sgreccia, M. Tamilvanan, M. Khadhraoui, C. Chassigneux, P. Knauth, J. Membr. Sci. 2010, $354,134$.

[27] E. Sgreccia, J. F. Chailan, M. Khadhraoui, M. L. Di Vona, P. Knauth, J. Power Sources 2010, 195, 7770.

[28] P. Knauth, E. Sgreccia, A. Donnadio, M. Casciola, M. L. Di Vona, J. Electrochem. Soc. 158, B159.

[29] M. L. Di Vona, G. Alberti, E. Sgreccia, M. Casciola, P. Knauth, Int. J. Hydrogen Energy 2012, 37, 8672.

[30] F. A. Carey, R. J. Sundberg, Advanced Organic Chemistry, Part A: Structure and Mechanisms 5th Edition, Springer, New York, USA, 2007.

[31] M. L. Di Vona, E. Sgreccia, S. Licoccia, M. Khadhraoui, R. Denoyel, P. Knauth, Chem. Mater. 2008, 20, 4327.

[32] S. M. J. Zaidi, S. D. Mikhailenko, G. P. Robertson, M. D. Guiver, S. Kaliaguine, J. Membr. Sci. 2000, 173, 17.

[33] P. Knauth, H. Hou, E. Bloch, E. Sgreccia, M. L. Di Vona, J. Anal. Appl. Pyrol. 2011, 92, 361.

[34] D. H. Rammler, A. Zaffaroni, Ann. New York Acad. Sci. 1967, 141, 13.

[35] A. J. Parker, Chem. Rev. 1969, 69, 1.

[36] A. J. Parker, Q. Rev., Chem. Soc. 1962, 16, 163.

[37] W. S. MacGregor, Ann. New York Acad. Sci. 1967, 141, 3.

[38] U. Mayer, V. Gutmann, W. Gerger, Monatshefte für Chemie - Chemical Monthly 1975, 106, 1235.

[39] I. M. Kolthoff, T. B. Reddy, Inorg. Chem. 1962, 1, 189.

[40] C. F. Bennet, in Technical Bulletin (105B) Reaction Solvent Dimethyl Sulfoxide, Gaylord Chemical Company, L.L.C.

[41] J. M. Alia, H. G. M. Edwards, B. M. Kiernan, Spectrochim. Acta Part A: Mol. Biomol. Spectrosc. 2004, 60, 1533.

[42] H. Meyer, Justus Liebigs Ann. Chem. 1923, 433, 327.

[43] B. M. Graybill, J. Org. Chem. 1967, 32, 2931.

[44] L. Field, J. Am. Chem. Soc. 1952, 74, 394.

[45] F. M. Collette, C. Lorentz, G. Gebel, F. Thominette, J. Membr. Sci. 2009, 330, 21.

[46] N. H. Christen, Acta Chem. Scand. 1966, 20, 1955. 
[47] F. M. Collette, F. Thominette, S. Escribano, A. Ravachol, A. Morin, G. Gebel, J. Power Sources 2012, 202, 126.

[48] M. Maroncelli, J. Macinnis, G. R. Fleming, Science 1989, 243, 1674 .

[49] D. Marani, M. L. Di Vona, E. Traversa, S. Licoccia, I. Beurroies, P. L. Llewellyn, P. Knauth, J. Phys. Chem. B 2006, 110, 15817.
[50] P. X. Xing, G. P. Robertson, M. D. Guiver, S. D. Mikhailenko, K. P. Wang, S. Kaliaguine, J. Membr. Sci. 2004, 229, 95.

[51] P. Cebe, J. Mater. Sci. 1988, 23, 3721. 